\title{
Professor Albert Defant siebzig Jahre
}

Professor Dr. Albert Defant, Ordinarius an der Universität und. Direktor des Instituts für Meteorologie und Geophysik in Innsbruck, vollendet am 12. Juli das siebzigste Lebensjahr. Der Weite seines Forschungsgebietes, das, zunächst auf die Meteorologie beschränkt, bereits seit Jahrzehnten die gesamte Dynamik der Atmosphäre und der Hydrosphäre umfaßt, entspricht es, daß die einzige heutige Fachzeitschrift in deutscher Sprache, deren Arbeitsbereich hiermit in Einklang steht, das ,Archiv für Meteorologie, Geophysik und Bioklimatologie“ das Sprachrohr der Geburtstagswünsche der Fachwelt bildet und den Strauß der Festaufsätze darbringt. Die Ozeanographen des Deutschen Hydrographischen Instituts haben sich gern der von dort aufgerufenen Schar der wissenschaftlichen Gratulanten angeschlossen im Gedenken besonders an die letzten Jahre, in denen der Jubilar während dreier Wintersemester als Gastprofessor die Meereskunde an der Universität Hamburg vertrat und ständiger gern gesehener Gast im Deutschen Hydrographischen Institut und in seiner Bibliothek war. Neben regem fachlichen Gedankenaustausch brachte dies die Neubelebung alter persönlicher Beziehungen aus den Jahren der, „Meteor" ${ }^{6}$-Fahrten und des Instituts für Meereskunde in Berlin. Zur Erinnerung an diese drei Hamburger ,Defant“"Wintersemester bringt die ,Deutsche Hydrographische Zeitschrift" einen Vortrag, den der Jubilar im letzten Wintersemester im Hamburger Geophysikalischen Kolloquium gehalten hat, mit einem herzlichen und zuversichtlichen ,ad multos annos" für den arbeitsfrohen Senior der aktiven Ozeanographen des deutschen Sprachbereichs und für den hochgeschätzten Mitarbeiter der „Deutschen Hydrographischen Zeitschrift". 